CENTRE FOR EMEA BANKING, FINANCE \& ECONOMICS

Is the consumption-income ratio stationary?

Evidence from linear and nonlinear panel unit root tests for OECD and non-OECD countries

Mario Cerrato, Christian de Peretti and Chris Stewart

Working Paper Series

No 09/11 


\title{
Is the consumption-income ratio stationary? Evidence from linear and nonlinear panel unit root tests for OECD and non-OECD countries
}

\author{
Mario Cerrato \\ Department of Economics \\ University of Glasgow \\ Christian de Peretti \\ Laboratory of Actuarial and Financial Sciences (SAF, EA2429), \\ Institute of Financial and Insurance Sciences, \\ University Claude Bernard Lyon 1, University of Lyon, France. \\ Chris Stewart ${ }^{1}$ \\ London Metropolitan Business School \\ London Metropolitan University
}

\begin{abstract}
This paper applies recently developed heterogeneous nonlinear and linear panel unit root tests that account for cross-sectional dependence to 24 OECD and 33 non-OECD countries' consumption-income ratios over the period 1951-2003. We apply a recently developed methodology that facilitates the use of panel tests to identify which individual cross-sectional units are stationary and which are nonstationary. This extends evidence provided in the recent literature to consider both linear and nonlinear adjustment in panel unit root tests, to address the issue of cross-sectional dependence, and to substantially expand both time-series and cross sectional dimensions of the data analysed. We find that the majority $(65 \%)$ of the series are nonstationary with slightly fewer OECD countries' (61\%) series exhibiting a unit root than non-OECD countries (68\%).
\end{abstract}

Key words: consumption-income ratio, heterogeneous panel nonlinear unit root test, crosssectional dependence, OECD and non-OECD countries

JEL classification: $\mathrm{C} 12, \mathrm{C} 33, \mathrm{D} 12$

\footnotetext{
${ }^{1}$ Chris Stewart, London Metropolitan Business School, London Metropolitan University, 84 Moorgate, London, EC2M 6SQ. Tel: 020-7320-1651. Fax: 020-7320-1585. E-mail: c.stewart@1ondonmet.ac.uk.
} 


\section{Introduction}

Economic theory generally suggests that the average propensity to consume (APC) is either constant or converges towards a constant. Hence, one expects the APC to be stationary. However, many empirical studies have presented evidence indicating that it is nonstationary, for example Sarantis and Stewart (1999), hereafter, SS. Arguably the adjustment of consumption (especially durables) is nonlinear and there have been many shocks since the 1950s that would force the APCs of many countries away from their equilibria (or change their equilibria). Hence, we utilise recently developed and heterogeneous panel unit root tests that allow for nonlinear adjustment towards equilibrium and that accommodate crosssectional dependence. We are not aware of any previous studies that have applied panel unit root tests that address cross-sectional dependence to the APC. Further, we apply these tests to 24 OECD and 33 non-OECD countries over the period 1951 to 2003 . We are not aware of any previous studies that apply unit root tests to such a broad range of countries (especially nonOECD) and over such a long time-span. Additionally, we utilise a recently developed procedure that facilitates the identification of which cross-sectional units are stationary and which are nonstationary using panel unit root tests rather than their less powerful time-series counterparts. Hence the novelty of the paper is in the application of nonlinear panel unit root tests that allow for cross-sectional dependence and identify which individual units are stationary/nonstationary to a dataset comprising a large number of countries over a long timespan.

The paper is organized as follows. Section 2 reviews the empirical and theoretical literature and discusses our data. Methods are discussed in Section 3 while the fourth section presents empirical results. Section 5 concludes the paper.

\section{Theory and empirics on the APC's stationarity}

Economic theory offers insight into whether the APC is stationary or not. Keynes's (1936) Absolute Income Hypothesis (AIH) implies that, as income grows, the APC converges towards a constant marginal propensity to consume (MPC). Assuming positive autonomous consumption and constant growth in aggregate income the aggregate APC should decline at a decreasing rate through time, converging towards the MPC.

Duesenberry's (1949) Relative Income Hypothesis (RIH) postulates that low income earners try to emulate consumption patterns of high income earners and so the former exhibit larger APCs than the latter. If a country's income distribution changes as income rises through time the aggregate APC may be trended, although it will be constant if the income distribution remains unchanged. The habit persistence form of the RIH implies a constant long-run APC provided that consumption grows at a constant rate.

Friedman's (1957) Permanent Income Hypothesis (PIH) may be interpreted as indicating a constant APC provided that the proportionality coefficient and transitory consumption and income are constant through time. Hadjimatheou (1987) notes that an implication of Modigliani's (1986) characterisation of the Life Cycle Hypothesis ( $\mathrm{LCH}$ ) is that a nation's saving rate is independent of its level of per-capita income and positively related to its longrun growth rate. Hence, a country's APC should be constant through time unless its long-run income growth rate changes. 
Davidson et al. (1978) utilise the microeconomic homogeneity postulate that consumption is homogeneous of degree one in income, which indicates a unit-income elasticity with respect to consumption. This implies that the equilibrium natural logarithm of the APC (LAPC) should be constant through time.

The theory cited above predominantly suggests a constant APC or, if it is trended, that it converges towards a constant. Thus, at least in terms of its mean, the APC should be stationary. Indeed, whilst not strictly bounded by zero and one the APC will never greatly exceed these values and it may, therefore, be regarded as unlikely to diverge without bound. Hence, there are strong theoretical reasons to believe the APC is stationary.

However, much evidence indicates that the APC is nonstationary. ${ }^{2}$ For example, SS demonstrate, using linear adjustment panel unit root tests, that LAPC is nonstationaryfor 20 OECD countries over the sample 1955-1994. One explanation is that if the APC declines at a decreasing rate through time (implied by the AIH), LAPC will likely feature a linear trend. These patterns are consistent with Figure 1 which plots the consumption-income ratio (CY and RCY) against income ( $\mathrm{Y}$ and RY) and its natural log (LCY and LRCY) against the natural $\log$ of income (LY and LRY) - where CY, Y, LCY and LY are measured in current prices and RCY, RY, LRCY and LRY are in constant prices. These graphs are given for OECD, Non-OECD and both OECD and Non-OECD (denoted All) countries. ${ }^{3}$ Data are obtained from version 6.2 of the Penn World Tables (Heston, Summers and Aten, 2006). ${ }^{4}$ Hence, we consider the possibility that LAPC is trend stationary.

Another potential explanation for the nonstationarityof LAPC is that the assumptions required for a constant APC do not hold. For example, if income growth shifts upwards the APC will shift downwards according to the LCH. Shifts in other factors, such as, inflation (Davidson et al, 1978), wealth (Hendry and Ungern-Sternberg, 1981), liquidity constraints (Miles, 1992), income uncertainty (Carroll, 1994), demographic factors (Horioka, 1997), interest rates (Hahm, 1998) and fiscal variables (Pesaran, Haque and Sharma, 2000) may also have shifted the APC. ${ }^{5}$ Cook (2005), using the same OECD data as SS, finds evidence that LAPC is stationary around a trend with intercept and slope shifts using the Lee and Strazicich (2003) time-series tests.

Whilst substantial changes have happened in many countries since 1950, abrupt structural breaks occurring in one period may not best characterise these changes. For example, Davidson et al (1978) argued that the 1973 upward shift in UK inflation caused the target

\footnotetext{
${ }^{2} \mathrm{SS}$ cite various papers where the APC is evidently nonstationary.

${ }^{3}$ The OECD countries are: Australia (AUS), Austria (AUT), Belgium (BEL), Canada (CAN), Denmark (DNK), Finland (FIN), France (FRA), Greece (GRC), Iceland (ISL), Ireland (IRL), Italy (ITA), Japan (JPN), Luxembourg (LUX), Mexico (MEX), Netherlands (NLD), New Zealand (NZL), Norway (NOR), Portugal (PRT), Spain (ESP), Sweden (SWE), Switzerland (CHE), Turkey (TUR), United Kingdom (GBR), United States of America (USA). The non-OECD countries are: Argentina (ARG), Bolivia (BOL), Brazil (BRA), Chile (CHL), Colombia (COL), Costa Rica (CRI), Dominican Republic (DOM), Ecuador (ECU), Egypt (EGY), El Salvador (SLV), Ethiopia (ETH), Guatemala (GTM), Honduras (HND), India (IND), Israel (ISR), Kenya (KEN), Mauritius (MUS), Morocco (MAR), Nicaragua (NIC), Nigeria (NGA), Pakistan (PAK), Panama (PAN), Paraguay (PRY), Peru (PER), Philippines (PHL), South Africa (ZAF), Sri Lanka (LKA), Taiwan (TWN), Thailand (THA), Trinidad and Tobago (TTO), Uganda (UGA), Uruguay (URY), Venezuela (VEN).

${ }^{4}$ In Heston et al (2006) $\mathrm{Y}$ is defined as real GDP per capita (denoted CGDP) in international dollars at current prices; RY as real GDP per capita (RGDPL) in international dollars at 2000 constant prices (Laspeyres); CY as the consumption share of CGDP (CC) measured as a percentage in current prices; RCY as the consumption share of RGDPL ( $\mathrm{kc})$ measured as a percentage in 2000 prices.

${ }^{5}$ Changes in income uncertainty alter precautionary savings and, according to the PIH, modify the APC.
} 
APC to shift downwards. However, due to slowness of adjustment the actual APC only gradually declined throughout the 1970s. Indeed, any durable component in consumption would likely be particularly slow to adjust. Further, financial deregulation that took place in many economies during the late twentieth century was a range of measures implemented over many years. Hence, the consequent changes in the APC would likely occur over several periods rather than just one. Thus, a test allowing for nonlinear adjustment towards a changing target APC may be appropriate than assuming that all countries are subject to intercept and slope shifts in a single period. ${ }^{6}$

The nonlinear test employed here yields adjustment towards equilibrium when the disequilibrium exceeds a particular threshold with little or no adjustment when the disequilibrium is below this threshold. However, a large disequilibrium will generally not be completely eliminated in one period but over many periods. Such nonlinear adjustment is particularly appropriate for the total consumption measures used here which embodies durable expenditures. This is because fixed adjustment costs may mean that consumers tolerate small departures from the equilibrium durable stock, however, once this disequilibrium exceeds a certain level the consumer abruptly adjusts consumption to make the deviation tolerable - see Caballero (1994).

\section{Testing methods}

This section discusses the nonlinear and linear panel unit root tests as well as the tests for cross-sectional dependence employed here. It also outlines a procedure for using panel unit root tests to determine whether each individual cross-sectional unit in the panel is stationary or nonstationary. In addition, we discuss the method used for identifying whether series are stationary, trend stationary or nonstationary.

\subsection{Cerrato et al's (2009) test}

Recently Cerrato, de Peretti, Larsson and Sarantis (2009), hereafter CPLS, proposed a nonlinear panel unit root test. This extends Kapetanios et al's (2003) time-series ESTAR test to a panel setting. The test is computed, under the unit root null, by estimating the following auxiliary regression: ${ }^{7}$

$$
\Delta y_{i t}=a_{i}+b_{i} y_{i, t-1}^{3}+\gamma_{i} f_{t}+u_{i t}
$$

where $y_{i t}$ on the $i^{\text {th }}$ cross-section at time $t$ is generated according to the ESTAR model, $f_{t}$ is a stationary factor accounting for cross-sectional dependence and $\gamma_{i}$ are country specific factor loadings. $f_{t}$ can be approximated by the two factors $\Delta \bar{y}_{t}=N^{-1} \sum_{j=1}^{N} \Delta y_{j t}$ and $\bar{y}_{t-1}{ }_{t-1}$, where ${\overline{y^{3}}}_{t-1}=N^{-1} \sum_{j=1}^{N} y_{j, t-1}^{3}$

\footnotetext{
${ }^{6}$ The tests employed by Cook (2005) have only two possible specifications: one shift in both intercept and slope or two shifts in intercept and slope. Many countries' APCs may not be best portrayed by either of these specifications.

${ }^{7}$ Note that in order to apply the test, as mentioned in Cerrato et al (2009), data should be first demeaned.
} 
The following test statistics for each individual time-series are computed: ${ }^{8}$

$$
t_{i N L}(N, T)=\frac{y_{i,-1}^{3} M \Delta y_{i}}{\left(\Delta y_{i}^{\prime} M \Delta y_{i}\right)^{1 / 2}\left(y_{i,-1}^{3} M y_{i,-1}^{3}\right)^{1 / 2}}
$$

where $\Delta y_{i}=\left(\Delta y_{i 1}, \Delta y_{i 2}, \ldots, \Delta y_{i, T}\right)^{\prime}, y_{i,-1}^{3}=\left(y_{i, 0}^{3}, y_{i, 1}^{3}, \ldots, y_{i, T-1}^{3}\right)^{\prime}, \quad M$ the projection onto $\delta(X)$, the orthogonal complement of the span of $X, \quad X=\left(\tau, \Delta \bar{y}, \bar{y}_{-1}^{3}\right)^{\prime}$, $\Delta \bar{y}=\left(\Delta \bar{y}_{1}, \Delta \bar{y}_{2}, \ldots, \Delta \bar{y}_{T}\right)^{\prime}, \bar{y}_{-1}^{3}=\left(\bar{y}_{0}^{3}, \bar{y}_{1}^{3}, \ldots, \bar{y}_{T-1}^{3}\right)$, and $\tau^{\prime}=(1,1, \ldots, 1)$.

The panel test is:

$$
\bar{t}_{N L}(N, T)=N^{-1} \sum_{i=1}^{N} t_{i N L}(N, T)
$$

CPLS tabulate critical values for different dimensions of time-series, $T$, and cross section, $N$ . Monte Carlo experiments showed that this test has better size and power than the Pesaran (2007) test when the data generating process (DGP) is nonlinear. Further, the model, and therefore the test, can include time trend and autocorrelation in the error terms:

$$
\Delta y_{i t}=a_{i}+\alpha_{i} t+b_{i} y_{i, t-1}^{3}+c_{i} \bar{y}_{t-1}^{3}+\sum_{j=0}^{p} d_{i j} \Delta \bar{y}_{t-j}+\sum_{j=1}^{p} \delta_{i j} \Delta y_{i t-j}+e_{i t}
$$

\subsection{Pesaran's (2007) test}

For comparative purposes we also report Pesaran's (2007) linear adjustment panel unit root test. It uses the following time-series regression which is estimated for each of the $\mathrm{N}$ crosssectional units.

$$
\Delta y_{i t}=a_{i}+\alpha_{i} t+b_{i} y_{i t-1}+c_{i} \bar{y}_{t-1}+\sum_{j=0}^{p} d_{i j} \Delta \bar{y}_{t-j}+\sum_{j=1}^{p} \delta_{i j} \Delta y_{i t-j}+e_{i t}
$$

when $\alpha_{i}=0$ we have the demeaned (intercept only) case and when $\alpha_{i} \neq 0$ we have the detrended (intercept and trend) case.

The CADF test statistic for each cross-section is the estimated OLS t-ratio corresponding to the coefficient $b_{i}$, denoted $t_{i}(N, T)$. The panel test statistic, CIPS, is:

$$
C I P S=N^{-1} \sum_{i=1}^{N} t_{i}(N, T)
$$

\footnotetext{
${ }^{8}$ Note that for the Common Correlated Effect estimator to work we require the factor $f_{t}$ to be stationary and that this could be restrictive in some empirical applications.
} 
Critical values for CIPS are given in Pesaran (2007). ${ }^{9}$

\subsection{Pesaran's (2004) cross-sectional dependence tests}

We also apply Pesaran's (2004) CD test for cross-sectional dependence in unbalanced panels to the residuals of $\mathrm{N}$ countries' time-series ADF test equations:

$C D=\sqrt{\frac{2}{N(N-1)}} \sum_{i=1}^{N-1} \sum_{j=i+1}^{N} \sqrt{T_{i j}} \hat{\rho}_{i j}^{*}$

where $\hat{\rho}_{i j}^{*}$ is the simple pairwise correlation coefficient of the residuals for cross-section $\mathrm{i}$ and j calculated over the sample period, of size $T_{i j}$, common to both sections. ${ }^{10}$ The statistic has a standard normal distribution asymptotically.

Pesaran (2004) demonstrates that CD is robust to structural breaks and unit roots in the DGP, is correctly sized (even in very small samples) and has satisfactory to high power. ${ }^{11}$

Pesaran (2004) specifies a modified version of a previously existing cross-sectional dependence test (which is also asymptotically standard normal) as: ${ }^{12}$

$C D_{l m}=\sqrt{\frac{1}{N(N-1)}} \sum_{i=1}^{N-1} \sum_{j=i+1}^{N}\left(T_{i j} \hat{\rho}_{i j}^{* 2}-1\right)$

Pesaran (2004) suggests that $C D_{l m}$ is likely to exhibit substantial size distortion when $\mathrm{N}$ is large and $\mathrm{T}$ is small and that this size distortion tends to worsen for fixed $\mathrm{T}$ as $\mathrm{N}$ increases.

\subsection{Identification of stationary and nonstationary series in the panel}

The strength of panel unit root tests where the null hypothesis is that all series in the panel are nonstationary and the alternative is that at least one series is stationary, is in the greater confidence in the determination of nonstationary series compared to time-series unit root tests due to the relatively greater power. An arguable drawback of the panel test is that it does not identify which, or how many, series are stationary when one rejects the null. We apply the methodology proposed by Stewart (2010) in the context of panel cointegration tests, modified

\footnotetext{
${ }^{9}$ None of our time-series tests were extreme, in terms of the thresholds identified in Pesaran (2007), and the truncated panel test was not required.

${ }^{10}$ The $\hat{\rho}_{i j}^{*}$ need to account for the possibility that the mean of the residuals for each section may not be zero for the common sample period used.

${ }^{11}$ One issue with this test is that it does not account for the possibility that positive and negative correlation coefficients may cancel in the weighted averages calculated in the statistics. Hence, a zero test statistic could be consistent with very large positive and negative correlation coefficients. To gauge the impact of cancelling we also calculate the average magnitude of the correlation coefficients, $|\overline{\hat{\rho}}|=\left(\frac{2}{N(N-1)}\right) \sum_{i=1}^{N-1} \sum_{j=i+1}^{N}\left|\hat{\rho}_{i j}\right|$.

${ }^{12}$ We adjust the test slightly to allow for the correlation coefficients to be estimated from different sample sizes for different country pairings.
} 
for panel unit root tests. This procedure utilises the improved power of the panel to distinguish which series in the panel are nonstationary and which are stationary.

We explain the procedure within the context of Pesaran's (2007) test although we also apply it using the CPLS test. If the $\mathrm{N}$ individual sections' t-ratios, $t_{i}(N, T)$, are ranked in descending order a set of $\mathrm{N}$ panel unit root statistics, CIPS , can be calculated for panels containing the first individual unit, the first and second units and so on.... The first CIPS statistic will be based on a panel of one individual cross-sectional unit, which has the largest value of $t_{i}(N, T)$ in the panel, and, therefore, will be least likely to reject the unit root null. Similarly, the second test statistic will be based on a panel of the two individual cross-sectional units with the two largest values of $t_{i}(N, T)$ in the panel, which will be the second least likely panel statistic to reject the null. In contrast, the $\mathrm{N}^{\text {th }}$ CIPS statistic will incorporate all the individual units in the panel and would be the most likely to reject the unit root null. Based on this set of $\mathrm{N}$ ordered panel statistics one can identify the individual cross-section where the panel test statistic first rejects the unit root null. If we let this test statistic contain $\mathrm{M}+1$ cross-sectional units then the previous panel unit root test that contained $\mathrm{M}$ units, did not reject the null that all units in this panel are nonstationary. This implies that it is the $\mathrm{M}+1^{\text {th }}$ cross-sectional unit, and only the $\mathrm{M}+1^{\text {th }}$ unit, that is stationary in the panel of $\mathrm{M}+1$ individuals. Our confidence in this result is as strong as our certainty of the power of the test for the panel involving $\mathrm{M}$ crosssections: if there is high power we can have confidence in the test's rejection that any series in the panel are stationary. Further, because the time-series t-ratio for $\mathrm{M}+2^{\text {th }}$ individual unit is less than that for the $\mathrm{M}+1^{\text {th }}$ unit, we know that had we replaced the latter by the former in the panel unit root test containing the $\mathrm{M}+1$ cross-sections, it would also reject the null. This implies that the series for units $\mathrm{M}+1$ and $\mathrm{M}+2$ are stationary. Indeed, it implies that units $\mathrm{M}+1, \mathrm{M}+2, \ldots, \mathrm{N}$ are all stationary. Hence, using this set of ordered panel unit root tests identifies the first $\mathrm{M}$ series as nonstationary and the remaining $(\mathrm{N}-\mathrm{M})$ units' series as stationary.

This method of identifying the order of integration of the units in the panel is superior to using the individual $t_{i}(N, T)$ statistics for two reasons. First, the panel test has superior power when $\mathrm{N}>1$, hence for $\mathrm{M}>1$ the panel method will have greater power than using individual unit root tests. Secondly, using statistics based upon a panel of one unit with accommodation for cross-sectional dependence is clearly inappropriate because if there is only one crosssectional unit there can be no cross-sectional dependence between units. In this case using standard time-series unit root tests (without adjustment for cross-sectional dependence) would be appropriate. However, these time-series tests still have lower power than the panel test and hence one should have more confidence in the panel test's inference compared to that of the time-series test. $^{13}$

\subsection{Determining whether series are stationary, trend stationary or nonstationary}

We distinguish between the hypotheses of a unit root, stationarity and trend stationarity as follows. If, using the test for demeaned data (intercept only), the unit root null hypothesis is rejected, the series is stationary. However, if the null is not rejected, the unit root test is applied to the demeaned and detrended data (intercept and trend). If the null hypothesis of this

\footnotetext{
${ }^{13}$ In our application we use an adjustment for cross-sectional dependence based on the averages of all $\mathrm{N}$ series in the panel and not solely the subset of units actually employed in constructing each test. We assume that this does not have an adverse influence on the test's results.
} 
test is rejected the series is trend stationary, whereas if the null is not rejected the variable has a unit root.

\section{Results}

Table 1 presents the tests for cross-sectional dependence based upon the residuals of timeseries ADF tests applied to each country's series. The tests are applied to all combinations of both OECD and Non-OECD country groupings, both LCY and LRCY series and ADF test equations including just an intercept and both an intercept and trend. For all eight combinations the magnitudes of both $C D$ and $C D_{l m}$ statistics exceed their $5 \%$ critical values. ${ }^{14}$ This unambiguously indicates the presence of cross-sectional dependence and justifies our use of panel unit root tests that account for such dependence.

Table 2 reports the results of Pesaran's (2007) cross-sectionally augmented time-series (column headed Time-series) and panel unit root (headed Panel) tests for LCY for OECD countries. The time-series tests are listed in descending order of size with those statistics least likely to reject the unit root null appearing higher up in the table. The panel statistic reported in the first row is a panel test including only one country (USA for the intercept only case and Mexico for the intercept and trend case). The panel statistic given in the second row is the panel test incorporating the first two countries listed in the table (USA and UK for the intercept only case and Mexico and Canada for the intercept and trend case). As we move down each row of the table another country (specified in the row) is added to the panel test until we reach the last row which contains the test statistic for the whole panel of, in this instance, 24 OECD countries. Comparing these statistics to their corresponding 5\% critical values (headed 5\% CV) we observe that, for the intercept only case, the panel tests for first 20 countries cannot reject the unit root null while the null is rejected for the last 4 countries. Hence, following the methodology discussed in Section 3.4, we conclude that LCY is stationary for Sweden, Iceland, Italy and Australia and nonstationary for the remaining 20 OECD countries.

To determine the form of nonstationarity we examine the panel test results for the case where both an intercept and trend are included in the test equations. We find that the first 12 panel tests cannot reject the unit root null whereas a unit root is rejected for the last 12 countries. Excluding the 4 countries that were found to be stationary (based on the intercept only case) from this latter group we therefore conclude that LCY is trend stationary for the following 8 OECD countries: Netherlands, UK, Turkey, Ireland, Spain, Austria, Denmark and New Zealand. Hence, LCY has a unit root for the remaining 12 OECD countries.

Pesaran's (2007) panel test results for LRCY for OECD countries are reported in Table 3. In this case 5 countries' series are stationary (Australia, Italy, New Zealand, Turkey and Iceland), none are trend stationary (given that LRCY for Iceland and New Zealand are stationary based upon the intercept only case) and the remaining 19 countries' series are nonstationary. The OECD countries where LRCY is stationary are either stationary or trend stationary for LCY, except for Sweden, which is stationary for LCY and nonstationary for LRCY. In general, there is less evidence against nonstationarity for LRCY than LCY in

\footnotetext{
${ }^{14}$ In all cases $|\overline{\hat{\rho}}|>\overline{\hat{\rho}}$, suggesting that the correlations between some residuals are negative and others are positive, causing some cancelling of the correlation coefficients using the $C D$ statistic.
} 
OECD countries using Pesaran's (2007) test and at least half the OECD countries' LAPCs are nonstationary.

The results from Pesaran's (2007) tests for non-OECD countries are reported in Tables 4 and 5 for LCY and LRCY, respectively. LCY is stationary for 12 of the 33 countries, trend stationary for a further 4 and nonstationary for the remaining 17 countries. Whereas LRCY is stationary for only 5 non-OECD countries, trend stationary for a further 2 and nonstationary for 26. Similar to the results for the OECD more countries are nonstationary for LRCY than LCY in non-OECD countries. ${ }^{15}$ Also, like the OECD countries' results, at least half of nonOECD countries' LAPCs are nonstationary.

The results of CPLS's nonlinear unit root test applied to OECD countries are reported for LCY and LRCY in Table 6 and 7, respectively. For LCY (LRCY) 8 (2) out of 24 LAPCs exhibit nonlinear mean reversion and a further 6 (4) feature nonlinear adjustment towards a trend. The remaining 10 (18) countries' LCYs (LRCYs) are nonstationary. Table 8 and 9 present the results of CPLS's test applied to non-OECD countries for LCY and LRCY, respectively. For LCY (LRCY) 4 (6) out of 33 countries exhibit nonlinear mean reversion and a further 6 (3) feature nonlinear adjustment towards a trend. The remaining 23 (24) countries' LCYs (LRCYs) are nonstationary. As for the results from Pesaran's test more countries' series are nonstationary for LRCY than LCY when using the nonlinear test. For OECD and non-OECD countries both tests indicate that the majority of LAPCs are nonstationary. While fewer OECD countries' series are nonstationary using CPLS's tests compared to Pesaran's (2007) the reverse is true for non-OECD countries. Approximately the same number of series is nonstationary for both tests.

\section{Conclusion}

Applying the method suggested by Stewart (2010) we utilize the greater power of panel unit root tests, relative to time-series tests, to determine whether the individual cross-sectional units in the panel are (trend) stationary or not. Considering all 228 tests conducted for OECD and non-OECD countries, both LCY and LRCY and using both linear and nonlinear panel unit root tests we find that the majority (149 or 65\%) indicate that LAPC is nonstationary. Thus, a minority of the results are consistent with the theoretical expectation of reversion to a mean or trend while the majority are in line with previous empirical findings of nonstationarity. However, this inference of a large percentage of nonstationary LAPCs is not theoretically implausible. For example, Molana (1989) suggests that an alternative to the "extreme" assumption that consumption has a unit-income elasticity is that consumption is homogeneous of degree one in life-time resources (income and wealth). If this latter hypothesis is true the LAPC will be nonstationary. This would suggest that consumption does not form an irreducible cointegrating vector solely with income - see Davidson (1998). ${ }^{16}$ Many theories suggest that variables beyond income determine equilibrium consumption which, if these variables are nonstationary, indicates that their inclusion in the consumption function may be necessary to achieve cointegration.

We find that 59 out of $96(61 \%)$ OECD countries' tests indicate nonstationarity whereas 90 of the $132(68 \%)$ non-OECD countries' results are nonstationary. Hence, there is slightly more

\footnotetext{
15 All countries that are stationary or trend stationary for LCY are stationary or trend stationary for LRCY, except for Thailand which is trend stationary for LRCY and nonstationary for LCY.

${ }^{16}$ An irreducible cointegrating vector is one that is cointegrated and the removal of any one variable from the vector causes the loss of cointegration.
} 
evidence of nonstationarity in non-OECD than OECD countries. Further, 62 of the 114 (54\%) tests for LCY indicate nonstationarity compared to 87 out of $114(76 \%)$ for LRCY. Hence, there is notably more evidence of nonstationarity for LRCY compared to LCY. Pesaran's (2007) and CPLS's tests indicate virtually the same number of series are nonstationarity (out of 114), being $74(65 \%)$ and 75 (66\%), respectively. However, these two tests do not provide exactly the same inference for every country and every measure of LAPC. Nevertheless, regardless of the test used, the measure employed or whether one considers OECD or nonOECD countries, the majority (but not all) of countries' series is nonstationary.

Our results contrast with SS who found, using linear reversion panel unit root tests that do not account for cross-sectional dependence, that all 20 OECD countries' LAPCs are nonstationary. Given that our OECD sample contains many of the countries in their sample we believe that our larger sample size, span of data and the use of tests that address crosssectional dependence explains the difference in results and suggests that our inferences are more reliable in terms of greater power. Our results also contrast with Cooke (2005) who, applying time-series tests using the same data as SS, find that all OECD countries' LAPCs are stationary around a shift in mean and/or trend. Our use of CPLS's test allows nonlinear adjustments and permits large abrupt changes, that could look like breaks, but that do not need to be confined to a single jump in one period. This would arguably be most appropriate for large adjustments due to, for example, financial deregulation taking place over several periods rather than in a single period. Once again we believe our results are more reliable due to the greater sample size and span as well as the form of test employed.

The results for non-OECD countries are, as far as we are aware, the first to be presented and therefore provide a reference and benchmark for future analyses of consumer behaviour in these countries. This is also the first application of a method that solely employs the relatively powerful panel unit root tests (and not time-series tests) to identify which cross-sectional units are stationary and nonstationary.

\section{References}

Caballero, R. J. (1994). "Notes on the theory and evidence on aggregate purchases of durable goods", Oxford Review of Economic Policy, Vol. 10, pp. 107 - 117.

Carroll, C. D. (1994). "How Does Future Income Affect Current Consumption?", Quarterly Journal of Economics, Vol. 109, pp. 111-147.

Cerrato, M., de Peretti, C., Larsson, R. and Sarantis, N. (2009). 'A nonlinear panel unit root test under cross-sectiondependence', Discussion Paper 2009-28, Department of Economics, University of Glasgow.

Cook, S. (2005). "The stationarity of consumption-income ratios: Evidence from minimum LM unit root testing”, Economics Letters, Vol. 89, pp. 55 - 60.

Davidson, J., (1998). "Structural relations, cointegration and identification: some simple results and their application", Journal of Econometrics, 87, 87 - 113.

Davidson, J. E. H., Hendry, D. F, Sbra, F. and Yeo, S. (1978). "Econometric Modelling of the Aggregate Time-Series Relationship Between Consumers' Expenditure and Income in the United Kingdom", Economic Journal, Vol. 80, pp. 661 - 692. 
Duesenberry, J. S. (1949). Income, Saving and the Theory of Consumer Behaviour. Harvard University Press, Cambridge, Mass..

Friedman, M. (1957). A Theory of the Consumption Function. Princeton University Press, Princeton, N.J..

Hadjimatheou, G. (1987). Consumer Economics After Keynes: Theory and Evidence of the Consumption Function. Wheatsheaf Books.

Hahm, J. (1998). "Consumption Adjustment to Real Interest Rates: Intertemporal Substitution Revisited”, Journal of Economic Dynamics and Control, Vol. 22, pp. 293 - 320.

Hendry, D. F. and Ungern-Sternberg, T. (1981). "Liquidity and Inflation Effects on Consumers' Expenditure". In Deaton Angus S (ed.), Essays in the Theory and Measurement of Consumer Behaviour in Honour of Sir Richard Stone, Cambridge University Press, pp. 237 260.

Heston, A., Summers, R. and Aten, B. (2006). Penn World Table Version 6.2, Center for International Comparisons of Production, Income and Prices at the University of Pennsylvania.

Horioka, C. Y. (1997). "A Cointegration Analysis of the Impact of the Age Structure of the Population on the Household Saving rate", Review of Economics and Statistics, Vol. 79, pp. $511-516$.

Kapetanios, G., Shin, Y. and Snell, A. (2003). "Testing for a Unit Root in the Nonlinear STAR Framework”, Journal of Econometrics, Vol. 112, pp. 359 - 379.

Keynes, J. M. (1936). The General Theory of Employment, Interest and Money. MacMillan, London.

Lee, J. and Strazicich, M. (2003). "Minimum LM Unit Root Test with Two Structural Breaks", Review of Economics and Statistics, Vol. 85, pp. 1082 - 1089.

Miles, D. (1992). "Housing Markets, Consumption and Financial Liberalisation in the Major Economies", European Economic Review, Vol. 36, pp. 1093 - 1136.

Modigliani, F. (1986). "Life Cycle, Individual Thrift, and the Wealth of Nations", American Economic Review, Vol. 76, pp. 1 - 19.

Molana, H. (1989). "Wealth, Allocation, Capital Gains and Private Expenditure in the UK", Scottish Journal of Political Economy, Vol. 36, pp. 209 - 237.

Pesaran M. H. (2004). "General Diagnostic Tests for Cross-sectionDependence in Panels" Centre for Economic Studies and Ifo Institute for Economic Research CESifo working paper no. 1229.

Pesaran, M. H. (2007). "A simple panel unit roor test in the presence of crosssectiondependence", Journal of Applied Econometrics, Vol. 22, pp. 265-312. 
Pesaran, M. H., Haque, N. U. and Sharma, S. (2000). "Neglected Heterogeneity and Dynamics in Cross Country Savings Regressions". In (eds) J. Krishnakumar and E. Ronchetti, Panel Data Econometrics - Future Direction: Papers in Honour of Professor Pietro Balestra. In the series, "Contributions to Economic Analysis", Elsevier Science, pp. 53 - 82.

Sarantis, N. and Stewart, C. (1999). "Is the Consumption-Income Ratio Stationary? Evidence from Panel Unit Root Tests”, Economics Letters, Vol. 64, pp. 309 - 314.

Stewart C. (2010). "Using panel cointegration tests to determine whether individual crosssectional units are cointegrated", mimeo, London Metropolitan University. 
Figure 1: APC Scatter Plots
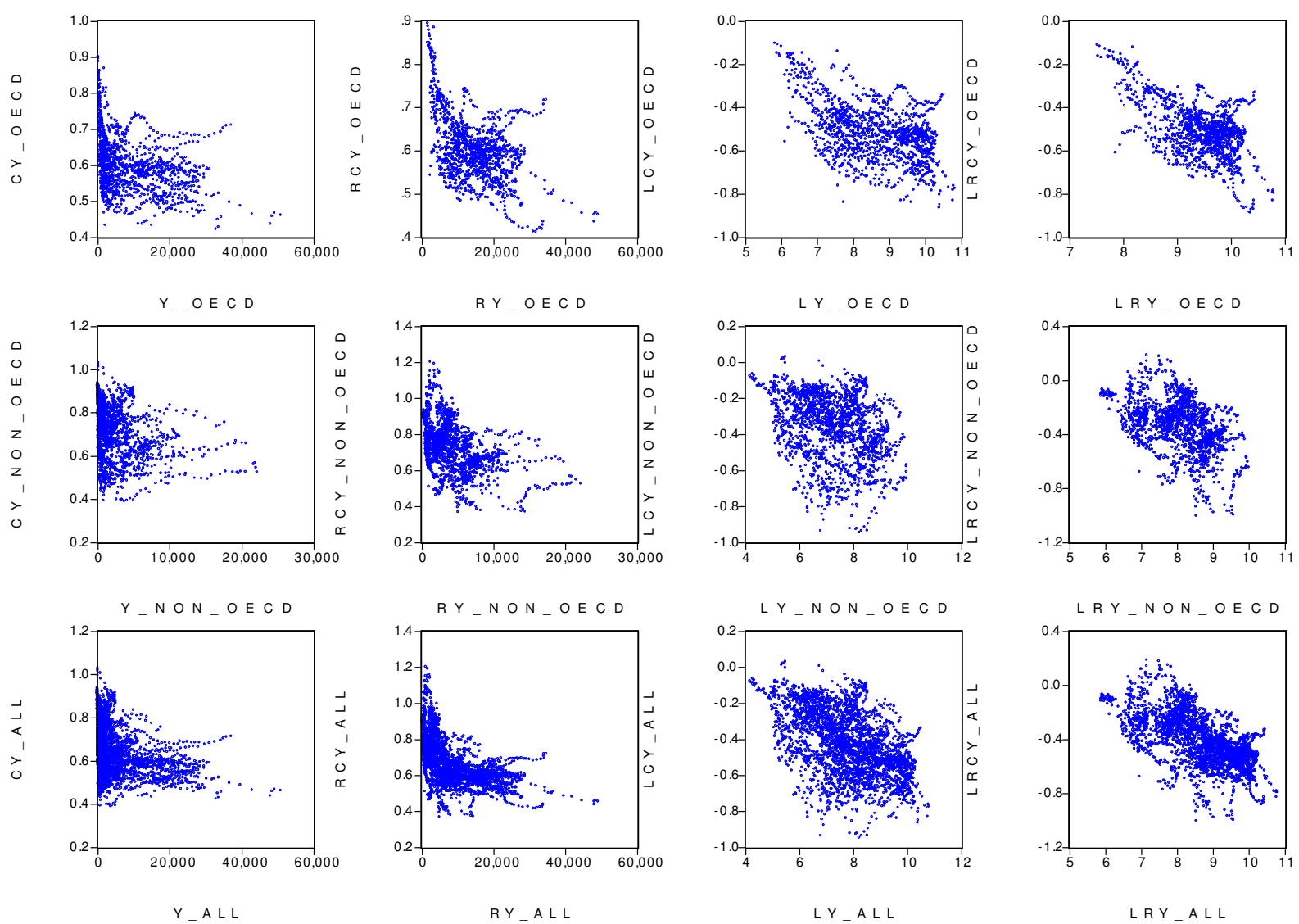

LY_A L L

L R Y A L L

These figures plot the (log of the) current price consumption-income ratio, CY (LCY), against (the log of) current income, Y (LY) and the (log of the) constant price consumptionincome ratio, LCY (LRCY), against (the log of the) constant price income, RY (LRY), for OECD, non-OECD and both OECD and non-OECD (denoted all) countries. 
Table 1: Cross-section dependence tests

\begin{tabular}{|c|c|c|c|c|}
\hline & \multicolumn{2}{|c|}{ OECD } & \multicolumn{2}{|c|}{ Non OECD } \\
\hline & LCY & LRCY & $\mathrm{LCY}$ & LRCY \\
\hline \multicolumn{5}{|c|}{ Intercept only } \\
\hline$\overline{\hat{\rho}}$ & 0.132 & 0.069 & 0.058 & 0.031 \\
\hline$|\overline{\hat{\rho}}|$ & 0.183 & 0.144 & 0.136 & 0.128 \\
\hline$C D$ & 15.771 & 8.299 & 9.548 & 5.137 \\
\hline$C D_{l m}$ & 17.978 & 7.784 & 8.667 & 4.600 \\
\hline \multicolumn{5}{|c|}{ Intercept and trend } \\
\hline$\overline{\hat{\rho}}$ & 0.145 & 0.069 & 0.069 & 0.028 \\
\hline$|\overline{\hat{\rho}}|$ & 0.193 & 0.145 & 0.142 & 0.130 \\
\hline$C D$ & 17.381 & 8.280 & 11.385 & 4.646 \\
\hline$C D_{l m}$ & 20.742 & 7.462 & 10.404 & 5.487 \\
\hline
\end{tabular}

$C D, C D_{l m}$, the average correlation coefficient, $\overline{\hat{\rho}}$, and the average magnitude of the correlation coefficient, $|\overline{\hat{\rho}}|$, are reported. These are based upon the residuals from standard ADF test equations for the $\left(\frac{N(N-1)}{2}\right)$ country pairings of OECD and nonOECD countries, respectively. The SBC is used to determine the lag length for the ADF regressions (allowing 0 to 3 lags) potentially causing sample sizes for the residual series to differ. Correlation coefficients are calculated using the common sample for each residual series pairing and sample sizes used for different pairings are potentially different. The critical values for both $C D$ and $C D_{l m}$ are \pm 1.96 . 
Table 2: Pesaran's (2007) test (OECD countries, LCY)

\begin{tabular}{|c|c|c|c|c|c|c|c|}
\hline \multicolumn{4}{|c|}{ Intercept only } & \multicolumn{4}{|c|}{ Intercept and Trend } \\
\hline Country & Time-series & Panel & $5 \% \mathrm{CV}$ & Country & Time-series & Panel & $5 \% \mathrm{CV}$ \\
\hline $\begin{array}{l}\text { USA } \\
\end{array}$ & -0.609 & -0.609 & -3.280 & MEX & -1.623 & -1.623 & -3.790 \\
\hline GBR & -0.710 & -0.660 & -3.174 & CAN & -2.254 & -1.939 & -3.684 \\
\hline IRL & -0.910 & -0.743 & -3.069 & LUX & -2.343 & -2.073 & -3.579 \\
\hline GRC & -1.135 & -0.841 & -2.963 & NOR & -2.406 & -2.157 & -3.473 \\
\hline MEX & -1.726 & -1.018 & -2.858 & CHE & -2.420 & -2.209 & -3.368 \\
\hline DNK & -1.755 & -1.141 & -2.752 & FRA & -2.673 & -2.287 & -3.262 \\
\hline LUX & -1.771 & -1.231 & -2.647 & BEL & -2.753 & -2.353 & -3.157 \\
\hline PRT & -1.952 & -1.321 & -2.541 & USA & -2.852 & -2.416 & -3.051 \\
\hline FRA & -2.338 & -1.434 & -2.436 & PRT & -2.859 & -2.465 & -2.946 \\
\hline JPN & -2.364 & -1.527 & -2.330 & JPN & -3.290 & -2.547 & -2.840 \\
\hline CHE & -2.404 & -1.607 & -2.314 & GRC & -3.561 & -2.639 & -2.824 \\
\hline CAN & -2.438 & -1.676 & -2.298 & FIN & -3.608 & -2.720 & -2.808 \\
\hline BEL & -2.451 & -1.736 & -2.282 & NLD & -3.650 & -2.792 & -2.792 \\
\hline FIN & -2.476 & -1.789 & -2.266 & GBR & -3.656 & -2.853 & -2.776 \\
\hline$\overline{\text { AUT }}$ & -2.629 & -1.845 & -2.250 & TUR & -3.784 & -2.915 & -2.760 \\
\hline NOR & -2.647 & -1.895 & -2.240 & IRL & -3.906 & -2.977 & -2.750 \\
\hline TUR & -2.904 & -1.954 & -2.230 & ESP & -4.118 & -3.044 & -2.740 \\
\hline ESP & -3.064 & -2.016 & -2.220 & SWE & -4.310 & -3.115 & -2.730 \\
\hline NLD & -3.566 & -2.097 & -2.210 & $\overline{\text { AUT }}$ & -4.502 & -3.188 & -2.720 \\
\hline NZL & -3.810 & -2.183 & -2.200 & DNK & -4.544 & -3.256 & -2.710 \\
\hline SWE & -3.844 & -2.262 & -2.196 & ISL & -4.700 & -3.324 & -2.704 \\
\hline ISL & -4.305 & -2.355 & -2.192 & ITA & -5.146 & -3.407 & -2.698 \\
\hline ITA & -4.463 & -2.447 & -2.188 & $\begin{array}{l}\mathbf{N Z L} \\
\end{array}$ & -5.490 & -3.498 & -2.692 \\
\hline AUS & -5.400 & -2.570 & -2.184 & AUS & -5.839 & -3.595 & -2.686 \\
\hline
\end{tabular}

This table reports $t_{i}(N, T)$, column headed Time-series, and CIPS, headed Panel. The panel test in row $i$ includes the first $i$ countries with the panel statistic in row 24 involving all 24 countries. The number of lags used in the individual country test equations is determined using SBC. The maximum available sample is $1951-2003$ which with 0 and 1 lags after differencing gives the individual country time-series sample sizes of 52 and 51 observations, respectively. $5 \%$ critical values are reported in the columns headed 5\% CV. For the intercept only case the critical value in the first row is taken from Table $1 \mathrm{~b}$ in Pesaran (2007) and corresponds to an individual time-series test with $\mathrm{T}=50$ and $\mathrm{N}=20$. The panel critical values reported in rows 10, 15, 20 (and implicitly 30) are taken from Table $2 \mathrm{~b}$ in Pesaran (2007) all for $\mathrm{T}=50$ and with $\mathrm{N}=10,15,20$ (and 30), respectively. The intervening critical values are calculated using linear interpolation. For the intercept and trend case critical values are taken from Tables 1c and 2c from Pesaran (2007) with intervening values also calculated using linear interpolation. A panel statistic highlighted with bold italic emphasis indicates rejection of the unit root null at the 5\% level. 
Table 3: Pesaran's (2007) test (OECD countries, LRCY)

\begin{tabular}{|c|c|c|c|c|c|c|c|}
\hline \multicolumn{4}{|c|}{ Intercept only } & \multicolumn{4}{|c|}{ Intercept and Trend } \\
\hline Country & Time-series & Panel & $5 \% \mathrm{CV}$ & Country & Time-series & Panel & $5 \% \mathrm{CV}$ \\
\hline GBR & -0.593 & -0.593 & -3.280 & LUX & -0.792 & -0.792 & -3.790 \\
\hline GRC & -0.828 & -0.711 & -3.174 & GBR & -1.021 & -0.907 & -3.684 \\
\hline MEX & -1.230 & -0.884 & -3.069 & IRL & -1.167 & -0.993 & -3.579 \\
\hline LUX & -1.234 & -0.971 & -2.963 & MEX & -1.215 & -1.049 & -3.473 \\
\hline IRL & -1.267 & -1.030 & -2.858 & NLD & -1.381 & -1.115 & -3.368 \\
\hline NOR & -1.350 & -1.084 & -2.752 & GRC & -1.838 & -1.236 & -3.262 \\
\hline NLD & -1.835 & -1.191 & -2.647 & PRT & -2.307 & -1.389 & -3.157 \\
\hline PRT & -1.846 & -1.273 & -2.541 & FIN & -2.388 & -1.514 & -3.051 \\
\hline FIN & -1.892 & -1.342 & -2.436 & CHE & -2.448 & -1.617 & -2.946 \\
\hline SWE & -2.273 & -1.435 & -2.330 & JPN & -2.533 & -1.709 & -2.840 \\
\hline CHE & -2.384 & -1.521 & -2.314 & NOR & -2.576 & -1.788 & -2.824 \\
\hline DNK & -2.727 & -1.622 & -2.298 & USA & -2.927 & -1.883 & -2.808 \\
\hline BEL & -2.731 & -1.707 & -2.282 & CAN & -2.987 & -1.968 & -2.792 \\
\hline JPN & -2.824 & -1.787 & -2.266 & ESP & -3.260 & -2.060 & -2.776 \\
\hline USA & -3.002 & -1.868 & -2.250 & FRA & -3.311 & -2.143 & -2.760 \\
\hline CAN & -3.003 & -1.939 & -2.240 & AUS & -3.316 & -2.217 & -2.750 \\
\hline FRA & -3.224 & -2.014 & -2.230 & BEL & -3.421 & -2.288 & -2.740 \\
\hline ESP & -3.292 & -2.085 & -2.220 & TUR & -3.507 & -2.355 & -2.730 \\
\hline AUT & -3.439 & -2.157 & -2.210 & DNK & -3.865 & -2.435 & -2.720 \\
\hline AUS & -3.465 & -2.222 & -2.200 & AUT & -4.025 & -2.514 & -2.710 \\
\hline ITA & -3.528 & -2.284 & -2.196 & SWE & -4.399 & -2.604 & -2.704 \\
\hline NZL & -3.568 & -2.343 & -2.192 & ITA & -4.543 & -2.692 & -2.698 \\
\hline TUR & -3.765 & -2.404 & -2.188 & ISL & -4.596 & -2.775 & -2.692 \\
\hline ISL & -4.705 & -2.500 & -2.184 & NZL & -5.308 & -2.880 & -2.686 \\
\hline
\end{tabular}

See Table 2 notes. 
Table 4: Pesaran's (2007) test (Non-OECD countries, LCY)

\begin{tabular}{|c|c|c|c|c|c|c|c|}
\hline \multicolumn{4}{|c|}{ Intercept only } & \multicolumn{4}{|c|}{ Intercept and Trend } \\
\hline Country & Time-series & Panel & $5 \% \mathrm{CV}$ & Country & Time-series & Panel & $5 \% \mathrm{CV}$ \\
\hline COL & 0.575 & 0.575 & -3.270 & PER & -1.209 & -1.209 & -3.800 \\
\hline IND & -1.135 & -0.280 & -3.166 & THA & -1.713 & -1.461 & -3.693 \\
\hline PER & -1.492 & -0.684 & -3.061 & COL & -1.786 & -1.569 & -3.587 \\
\hline BRA & -1.534 & -0.897 & -2.957 & TWN & -1.858 & -1.642 & -3.480 \\
\hline ECU & -1.615 & -1.040 & -2.852 & NIC & -2.122 & -1.738 & -3.373 \\
\hline ISR & -1.898 & -1.183 & -2.748 & IND & -2.150 & -1.806 & -3.267 \\
\hline THA & -1.917 & -1.288 & -2.643 & PAK & -2.307 & -1.878 & -3.160 \\
\hline NIC & -2.101 & -1.390 & -2.539 & ARG & -2.529 & -1.959 & -3.053 \\
\hline KEN & -2.314 & -1.492 & -2.434 & $\overline{\text { BOL }}$ & -2.590 & -2.029 & -2.947 \\
\hline PAK & -2.364 & -1.580 & -2.330 & ISR & -2.764 & -2.103 & -2.840 \\
\hline TWN & -2.366 & -1.651 & -2.314 & PHL & -2.804 & -2.167 & -2.824 \\
\hline CRI & -2.552 & -1.726 & -2.298 & $\overline{\text { BRA }}$ & -3.103 & -2.245 & -2.808 \\
\hline BOL & -2.57 & -1.791 & -2.282 & URY & -3.162 & -2.315 & -2.792 \\
\hline PHL & -2.603 & -1.849 & -2.266 & KEN & -3.240 & -2.381 & -2.776 \\
\hline$\overline{\text { ARG }}$ & -2.701 & -1.906 & -2.250 & LKA & -3.269 & -2.440 & -2.760 \\
\hline TTO & -2.701 & -1.956 & -2.240 & TTO & -3.288 & -2.493 & -2.750 \\
\hline LKA & -2.814 & -2.006 & -2.230 & ECU & -3.441 & -2.549 & -2.740 \\
\hline VEN & -2.854 & -2.053 & -2.220 & GTM & -3.460 & -2.600 & -2.730 \\
\hline NGA & -2.995 & -2.103 & -2.210 & VEN & -3.462 & -2.645 & -2.720 \\
\hline CHL & -3.019 & -2.149 & -2.200 & DOM & -3.565 & -2.691 & -2.710 \\
\hline PAN & -3.061 & -2.192 & -2.196 & CHL & -3.726 & -2.740 & -2.704 \\
\hline URY & -3.264 & -2.241 & -2.192 & NGA & -3.769 & -2.787 & -2.698 \\
\hline GTM & -3.317 & -2.287 & -2.188 & HND & -4.122 & -2.845 & -2.692 \\
\hline SLV & -3.322 & -2.331 & -2.184 & $\overline{\text { ZAF }}$ & -4.169 & -2.900 & -2.686 \\
\hline UGA & -3.411 & -2.374 & -2.180 & PAN & -4.322 & -2.957 & -2.680 \\
\hline DOM & -3.629 & -2.422 & -2.176 & CRI & -4.357 & -3.011 & -2.674 \\
\hline MAR & -3.672 & -2.468 & -2.172 & EGY & -4.433 & -3.064 & -2.668 \\
\hline PRY & -3.677 & -2.512 & -2.168 & PRY & -4.670 & -3.121 & -2.662 \\
\hline EGY & -3.733 & -2.554 & -2.164 & MAR & -4.812 & -3.179 & -2.656 \\
\hline HND & -4.048 & -2.603 & -2.160 & ETH & -5.255 & -3.249 & -2.650 \\
\hline ETH & -4.287 & -2.658 & -2.155 & UGA & -5.313 & -3.315 & -2.645 \\
\hline ZAF & -4.467 & -2.714 & -2.150 & SLV & -5.344 & -3.379 & -2.640 \\
\hline MUS & -5.608 & -2.802 & -2.145 & MUS & -5.927 & -3.456 & -2.635 \\
\hline
\end{tabular}

See Table 2 notes, except critical values from Pesaran's (2007) Table 1b and 1c for T $=50$ and $\mathrm{N}=30$ are reported in the first row. In addition, critical values for $\mathrm{T}=50$ and $\mathrm{N}=50$ from Pesaran's Table $2 \mathrm{~b}$ and $2 \mathrm{c}$ are also implicitly used to calculate the reported critical values. 
Table 5: Pesaran's (2007) test (Non-OECD countries, LRCY)

\begin{tabular}{|c|c|c|c|c|c|c|c|}
\hline \multicolumn{4}{|c|}{ Intercept only } & \multicolumn{4}{|c|}{ Intercept and Trend } \\
\hline Country & Time-series & Panel & $5 \% \mathrm{CV}$ & Country & Time-series & Panel & $5 \% \mathrm{CV}$ \\
\hline COL & 0.251 & 0.251 & -3.270 & ISR & -0.436 & -0.436 & -3.800 \\
\hline ISR & -0.594 & -0.172 & -3.166 & TWN & -1.003 & -0.720 & -3.693 \\
\hline TWN & -0.981 & -0.441 & -3.061 & PER & -1.460 & -0.966 & -3.587 \\
\hline BRA & -1.610 & -0.734 & -2.957 & DOM & -1.867 & -1.192 & -3.480 \\
\hline DOM & -1.637 & -0.914 & -2.852 & BOL & -2.032 & -1.360 & -3.373 \\
\hline PER & -1.647 & -1.036 & -2.748 & EGY & -2.051 & -1.475 & -3.267 \\
\hline NIC & -1.735 & -1.136 & -2.643 & VEN & -2.063 & -1.559 & -3.160 \\
\hline VEN & -1.813 & -1.221 & -2.539 & URY & -2.098 & -1.626 & -3.053 \\
\hline CRI & -1.947 & -1.301 & -2.434 & CRI & -2.171 & -1.687 & -2.947 \\
\hline IND & -1.981 & -1.369 & -2.330 & NIC & -2.188 & -1.737 & -2.840 \\
\hline THA & -1.985 & -1.425 & -2.314 & COL & -2.192 & -1.778 & -2.824 \\
\hline URY & -2.029 & -1.476 & -2.298 & $\overline{E C U}$ & -2.519 & -1.840 & -2.808 \\
\hline EGY & -2.058 & -1.520 & -2.282 & LKA & -2.553 & -1.895 & -2.792 \\
\hline PHL & -2.091 & -1.561 & -2.266 & GTM & -2.603 & -1.945 & -2.776 \\
\hline TTO & -2.205 & -1.604 & -2.250 & ARG & -2.628 & -1.991 & -2.760 \\
\hline ETH & -2.297 & -1.647 & -2.240 & PHL & -2.639 & -2.031 & -2.750 \\
\hline BOL & -2.355 & -1.689 & -2.230 & PAK & -2.649 & -2.068 & -2.740 \\
\hline CHL & -2.490 & -1.734 & -2.220 & MUS & -2.708 & -2.103 & -2.730 \\
\hline GTM & -2.604 & -1.779 & -2.210 & CHL & -2.834 & -2.142 & -2.720 \\
\hline UGA & -2.652 & -1.823 & -2.200 & TTO & -2.840 & -2.177 & -2.710 \\
\hline ARG & -2.660 & -1.863 & -2.196 & IND & -2.899 & -2.211 & -2.704 \\
\hline ECU & -2.695 & -1.901 & -2.192 & BRA & -3.003 & -2.247 & -2.698 \\
\hline KEN & -2.705 & -1.936 & -2.188 & PAN & -3.221 & -2.289 & -2.692 \\
\hline PAK & -2.853 & -1.974 & -2.184 & UGA & -3.530 & -2.341 & -2.686 \\
\hline LKA & -2.902 & -2.011 & -2.180 & KEN & -3.555 & -2.390 & -2.680 \\
\hline MUS & -2.949 & -2.047 & -2.176 & $\mathbf{Z A F}$ & -3.572 & -2.435 & -2.674 \\
\hline ZAF & -3.134 & -2.087 & -2.172 & NGA & -3.620 & -2.479 & -2.668 \\
\hline PRY & -3.195 & -2.127 & -2.168 & SLV & -3.801 & -2.526 & -2.662 \\
\hline NGA & -3.203 & -2.164 & -2.164 & MAR & -3.966 & -2.576 & -2.656 \\
\hline PAN & -3.372 & -2.204 & -2.160 & PRY & -4.180 & -2.629 & -2.650 \\
\hline SLV & -3.860 & -2.258 & -2.155 & THA & -4.313 & -2.684 & -2.645 \\
\hline MAR & -3.946 & -2.310 & -2.150 & ETH & -4.634 & -2.745 & -2.640 \\
\hline HND & -4.998 & -2.392 & -2.145 & HND & -5.285 & -2.822 & -2.635 \\
\hline
\end{tabular}

See Table 2 and Table 4 notes. 
Table 6: CPLS's test (OECD countries, LCY)

\begin{tabular}{|c|c|c|c|c|c|c|c|}
\hline \multicolumn{4}{|c|}{ Intercept } & \multicolumn{5}{c|}{ Intercept and trend } \\
\hline Country & Time-series & Panel & $\mathbf{5 \%}$ CV & Country & Time-series & Panel & $\mathbf{5 \%}$ CV \\
\hline USA & -0.109 & -0.109 & -3.040 & MEX & -1.510 & -1.510 & -3.470 \\
\hline GRC & -1.554 & -0.832 & -2.942 & NOR & -1.600 & -1.555 & -3.551 \\
\hline IRL & -1.558 & -1.074 & -2.844 & CAN & -1.640 & -1.583 & -3.433 \\
\hline PRT & -1.681 & -1.226 & -2.747 & USA & -2.070 & -1.705 & -3.315 \\
\hline GBR & -1.717 & -1.324 & -2.649 & SWE & -2.220 & -1.808 & -3.197 \\
\hline LUX & -1.769 & -1.398 & -2.551 & PRT & -2.290 & -1.888 & -3.079 \\
\hline ITA & -1.836 & -1.461 & -2.453 & CHE & -2.330 & -1.951 & -2.961 \\
\hline ISL & -1.881 & -1.513 & -2.356 & GBR & -2.330 & -1.999 & -2.843 \\
\hline MEX & -2.191 & -1.588 & -2.258 & FIN & -2.600 & -2.066 & -2.725 \\
\hline CAN & -2.201 & -1.650 & -2.160 & ISL & -2.620 & -2.121 & -2.607 \\
\hline FRA & -2.261 & -1.705 & -2.144 & LUX & -2.860 & -2.188 & -2.588 \\
\hline CHE & -2.305 & -1.755 & -2.128 & GRC & -2.940 & -2.251 & -2.568 \\
\hline NLD & -2.445 & -1.808 & -2.112 & BEL & -3.180 & -2.322 & -2.549 \\
\hline TUR & -2.639 & -1.868 & -2.096 & JAP & -3.280 & -2.391 & -2.530 \\
\hline NOR & -3.098 & -1.950 & -2.080 & ESP & -3.330 & -2.453 & -2.510 \\
\hline DNK & -3.124 & -2.023 & -2.074 & NLD & -3.430 & $\mathbf{- 2 . 5 1 4}$ & -2.503 \\
\hline BEL & -3.158 & $\mathbf{- 2 . 0 9 0}$ & -2.068 & FRA & -3.440 & $\mathbf{- 2 . 5 6 9}$ & -2.496 \\
\hline SWE & -3.762 & $\mathbf{- 2 . 1 8 3}$ & -2.062 & AUT & -3.820 & $\mathbf{- 2 . 6 3 8}$ & -2.489 \\
\hline NZL & -3.788 & $\mathbf{- 2 . 2 6 7}$ & -2.056 & ITA & -3.840 & $\mathbf{- 2 . 7 0 2}$ & -2.481 \\
\hline FIN & -3.807 & $\mathbf{- 2 . 3 4 4}$ & -2.050 & DNK & -4.130 & $\mathbf{- 2 . 7 7 3}$ & -2.474 \\
\hline JAP & -3.991 & $\mathbf{- 2 . 4 2 3}$ & -2.045 & TUR & -4.870 & $\mathbf{- 2 . 8 7 3}$ & -2.468 \\
\hline AUT & -4.001 & $\mathbf{- 2 . 4 9 4}$ & -2.040 & AUS & -4.970 & $\mathbf{- 2 . 9 6 8}$ & -2.462 \\
\hline ESP & -4.969 & $\mathbf{- 2 . 6 0 2}$ & -2.035 & IRL & -5.470 & $\mathbf{- 3 . 0 7 7}$ & -2.456 \\
\hline AUS & -5.245 & $\mathbf{- 2 . 7 1 2}$ & -2.030 & NZL & -7.220 & $\mathbf{- 3 . 2 5 0}$ & -2.450 \\
\hline
\end{tabular}

This table reports the unit root test results using cross-sectional means in the regression for both individual countries (in the column headed Time-series) and panel (Panel). The panel test reported in row $i$ uses a panel of the first $i$ countries. The number of lags used in the individual country test equations is determined using SBC. The maximum available sample is $1951-2003$. 5\% critical values based on CPLS are reported in the columns headed 5\% CV. For the intercept only case the critical value in the first row is taken from Table 11 in CPLS and corresponds to an individual time-series test with $\mathrm{T}=50$ and $\mathrm{N}=20$. The panel critical values reported in rows $10,15,20$ (and implicitly 30) are taken from Table 12 in CPLS all for $\mathrm{T}=50$ and with $\mathrm{N}=10,15,20$ (and 30), respectively. The intervening critical values are calculated using linear interpolation. For the intercept and trend case we generated critical values for row 1 (a time-series test with $\mathrm{N}=24$ and $\mathrm{T}=50$ ) and row 24 (a panel test with $\mathrm{N}=24$ and $\mathrm{T}=50$ ), the latter we denote $\mathrm{CV}_{24}$. To obtain the intervening values we applied the growth rate (as a country is added to the panel) of the critical values for the intercept only case to the first critical value for intercept and trend and repeated this recursively to obtain initial critical values for all panel sizes including an initial value for the whole panel, denoted $\mathrm{I}_{24}$. We then multiplied all of these initial values by $\left(\mathrm{CV}_{24} / \mathrm{I}_{24}\right)$ to obtain the reported critical values. A panel statistic highlighted with bold italic emphasis indicates rejection of the unit root null. 
Table 7: CPLS's test (OECD countries, LRCY)

\begin{tabular}{|c|c|c|c|c|c|c|c|}
\hline \multicolumn{9}{|c}{ Intercept } & \multicolumn{4}{c|}{ Intercept and trend } \\
\hline Country & Time-series & Panel & $\mathbf{5 \%}$ CV & Country & Time-series & Panel & 5\% CV \\
\hline PRT & -0.877 & -0.877 & -3.040 & GBR & -1.501 & -1.501 & -3.470 \\
\hline SWE & -0.993 & -0.935 & -2.942 & IRL & -1.530 & -1.516 & -3.551 \\
\hline GBR & -1.002 & -0.957 & -2.844 & NLD & -1.550 & -1.527 & -3.433 \\
\hline ITA & -1.177 & -1.012 & -2.747 & SWE & -1.640 & -1.555 & -3.315 \\
\hline IRL & -1.209 & -1.052 & -2.649 & ITA & -1.900 & -1.624 & -3.197 \\
\hline NOR & -1.286 & -1.091 & -2.551 & GRC & -2.200 & -1.720 & -3.079 \\
\hline NLD & -1.376 & -1.131 & -2.453 & CHE & -2.360 & -1.812 & -2.961 \\
\hline GRC & -1.442 & -1.170 & -2.356 & BEL & -2.560 & -1.905 & -2.843 \\
\hline MEX & -1.601 & -1.218 & -2.258 & JAP & -2.600 & -1.982 & -2.725 \\
\hline JAP & -1.694 & -1.266 & -2.160 & USA & -2.660 & -2.050 & -2.607 \\
\hline USA & -1.740 & -1.309 & -2.144 & MEX & -2.700 & -2.109 & -2.588 \\
\hline CHE & -1.758 & -1.346 & -2.128 & CAN & -2.740 & -2.162 & -2.568 \\
\hline CAN & -2.005 & -1.397 & -2.112 & PRT & -2.800 & -2.211 & -2.549 \\
\hline LUX & -2.273 & -1.460 & -2.096 & FIN & -2.970 & -2.265 & -2.530 \\
\hline BEL & -2.441 & -1.525 & -2.080 & AUS & -3.060 & -2.318 & -2.510 \\
\hline AUT & -2.741 & -1.601 & -2.074 & DNK & -3.060 & -2.364 & -2.503 \\
\hline DNK & -2.831 & -1.673 & -2.068 & NZL & -3.089 & -2.407 & -2.496 \\
\hline FIN & -2.831 & -1.738 & -2.062 & AUT & -3.180 & -2.450 & -2.489 \\
\hline ESP & -2.863 & -1.797 & -2.056 & NOR & -3.490 & $\mathbf{- 2 . 5 0 5}$ & -2.481 \\
\hline AUS & -3.191 & -1.867 & -2.050 & ISL & -3.900 & $\mathbf{- 2 . 5 7 5}$ & -2.474 \\
\hline NZL & -3.191 & -1.930 & -2.045 & LUX & -3.940 & $\mathbf{- 2 . 6 4 0}$ & -2.468 \\
\hline FRA & -3.318 & -1.993 & -2.040 & FRA & -4.250 & $\mathbf{- 2 . 7 1 3}$ & -2.462 \\
\hline ISL & -3.839 & $-\mathbf{- 2 . 0 7 3}$ & -2.035 & ESP & -4.330 & $\mathbf{- 2 . 7 8 3}$ & -2.456 \\
\hline TUR & -3.895 & $-\mathbf{2 . 1 4 9}$ & -2.030 & TUR & -5.490 & $\mathbf{- 2 . 8 9 6}$ & -2.450 \\
\hline
\end{tabular}

See Table 6 notes. 
Table 8: CPLS's test (Non-OECD countries, LCY)

\begin{tabular}{|c|c|c|c|c|c|c|c|}
\hline \multicolumn{4}{|c|}{ Intercept } & \multicolumn{4}{|c|}{ Intercept and trend } \\
\hline Country & Time-series & Panel & $5 \% \mathrm{CV}$ & Country & Time-series & Panel & $5 \% \mathrm{CV}$ \\
\hline COL & -0.374 & -0.374 & -3.060 & ISR & -0.840 & -0.840 & -3.480 \\
\hline IND & -0.814 & -0.594 & -2.960 & ARG & -1.230 & -1.035 & -3.592 \\
\hline ISR & -0.936 & -0.708 & -2.860 & THA & -1.240 & -1.103 & -3.471 \\
\hline THA & -0.984 & -0.777 & -2.760 & PHL & -1.380 & -1.173 & -3.350 \\
\hline ECU & -1.164 & -0.854 & -2.660 & URY & -1.730 & -1.284 & -3.228 \\
\hline BRA & -1.248 & -0.920 & -2.560 & BRA & -1.840 & -1.377 & -3.107 \\
\hline PHL & -1.251 & -0.967 & -2.460 & TTO & -1.890 & -1.450 & -2.986 \\
\hline ARG & -1.333 & -1.013 & -2.360 & ECU & -1.900 & -1.506 & -2.864 \\
\hline KEN & -1.362 & -1.052 & -2.260 & TWN & -1.960 & -1.557 & -2.743 \\
\hline TWN & -1.463 & -1.093 & -2.160 & PER & -2.000 & -1.601 & -2.621 \\
\hline URY & -1.466 & -1.127 & -2.144 & COL & -2.300 & -1.665 & -2.602 \\
\hline NIC & -1.597 & -1.166 & -2.128 & PRY & -2.390 & -1.725 & -2.583 \\
\hline BOL & -1.639 & -1.202 & -2.112 & IND & -2.580 & -1.791 & -2.563 \\
\hline PER & -1.761 & -1.242 & -2.096 & EGY & -2.600 & -1.849 & -2.544 \\
\hline TTO & -1.978 & -1.291 & -2.080 & PAK & -2.660 & -1.903 & -2.524 \\
\hline NGA & -2.065 & -1.340 & -2.074 & DOM & -2.840 & -1.961 & -2.517 \\
\hline PAK & -2.268 & -1.394 & -2.068 & HND & -2.840 & -2.013 & -2.510 \\
\hline EGY & -2.417 & -1.451 & -2.062 & CRI & -3.020 & -2.069 & -2.503 \\
\hline PAN & -2.469 & -1.505 & -2.056 & BOL & -3.180 & -2.127 & -2.495 \\
\hline GTM & -2.554 & -1.557 & -2.050 & CHL & -3.450 & -2.194 & -2.488 \\
\hline HND & -2.576 & -1.606 & -2.045 & SLV & -3.480 & -2.255 & -2.482 \\
\hline PRY & -2.594 & -1.651 & -2.040 & LKA & -3.540 & -2.313 & -2.476 \\
\hline DOM & -2.633 & -1.693 & -2.035 & NGA & -3.640 & -2.371 & -2.470 \\
\hline CRI & -2.644 & -1.733 & -2.030 & GTM & -3.730 & -2.428 & -2.464 \\
\hline MAR & -2.674 & -1.771 & -2.025 & VEN & -3.850 & -2.484 & -2.458 \\
\hline ZAF & -2.899 & -1.814 & -2.020 & PAN & -3.890 & -2.538 & -2.452 \\
\hline SLV & -3.143 & -1.863 & -2.015 & KEN & -3.900 & -2.589 & -2.445 \\
\hline CHL & -3.300 & -1.915 & -2.010 & ZAF & -3.930 & -2.637 & -2.439 \\
\hline ETH & -3.457 & -1.968 & -2.005 & MAR & -3.950 & -2.682 & -2.433 \\
\hline VEN & -3.579 & -2.021 & -2.000 & NIC & -4.280 & -2.735 & -2.427 \\
\hline LKA & -3.629 & -2.073 & -1.998 & ETH & -4.550 & -2.794 & -2.425 \\
\hline UGA & -4.353 & -2.145 & -1.996 & UGA & -5.140 & -2.867 & -2.422 \\
\hline MUS & -5.899 & -2.258 & -1.994 & MUS & -6.230 & -2.969 & -2.420 \\
\hline
\end{tabular}

See Table 6 notes, except that critical from CPLS's Table 11 for $\mathrm{T}=50$ and $\mathrm{N}=30$ is reported in the first row for the intercept only case. In addition, the critical values for $\mathrm{T}=50$ and $\mathrm{N}=50$ from Table 12 are also implicitly used to calculate the reported critical values for the intercept only case. For the intercept and trend tests we simulated the critical values for the first and last row of the table and employed the procedure discussed in Table 6 to calculate the intervening critical values. 
Table 9: CPLS's test (Non-OECD countries, LRCY)

\begin{tabular}{|c|c|c|c|c|c|c|c|}
\hline \multicolumn{4}{|c|}{ Intercept } & \multicolumn{4}{|c|}{ Intercept and trend } \\
\hline Country & Time-series & Panel & $5 \% \mathrm{CV}$ & Country & Time-series & Panel & $5 \% \mathrm{CV}$ \\
\hline COL & -0.637 & -0.637 & -3.060 & ISR & -0.930 & -0.930 & -3.480 \\
\hline ISR & -0.736 & -0.687 & -2.960 & BOL & -0.950 & -0.940 & -3.592 \\
\hline NGA & -0.802 & -0.725 & -2.860 & COL & -1.086 & -0.989 & -3.471 \\
\hline BRA & -0.828 & -0.751 & -2.760 & CRI & -1.440 & -1.102 & -3.350 \\
\hline PER & -0.876 & -0.776 & -2.660 & ECU & -1.450 & -1.171 & -3.228 \\
\hline BOL & -1.198 & -0.846 & -2.560 & URY & -1.450 & -1.218 & -3.107 \\
\hline TWN & -1.421 & -0.928 & -2.460 & ARG & -1.690 & -1.285 & -2.986 \\
\hline CRI & -1.697 & -1.024 & -2.360 & BRA & -1.710 & -1.338 & -2.864 \\
\hline ARG & -1.699 & -1.099 & -2.260 & PER & -1.910 & -1.402 & -2.743 \\
\hline IND & -1.784 & -1.168 & -2.160 & TWN & -2.130 & -1.475 & -2.621 \\
\hline MUS & -1.976 & -1.241 & -2.144 & SLV & -2.220 & -1.542 & -2.602 \\
\hline UGA & -1.993 & -1.304 & -2.128 & DOM & -2.230 & -1.600 & -2.583 \\
\hline ETH & -2.022 & -1.359 & -2.112 & ETH & -2.400 & -1.661 & -2.563 \\
\hline ECU & -2.027 & -1.407 & -2.096 & GTM & -2.660 & -1.733 & -2.544 \\
\hline DOM & -2.148 & -1.456 & -2.080 & TTO & -2.710 & -1.798 & -2.524 \\
\hline NIC & -2.161 & -1.500 & -2.074 & PHL & -2.790 & -1.860 & -2.517 \\
\hline EGY & -2.459 & -1.557 & -2.068 & ZAF & -2.970 & -1.925 & -2.510 \\
\hline PHL & -2.501 & -1.609 & -2.062 & PAK & -2.980 & -1.984 & -2.503 \\
\hline TTO & -2.614 & -1.662 & -2.056 & IND & -2.990 & -2.037 & -2.495 \\
\hline PRY & -2.687 & -1.713 & -2.050 & CHL & -3.080 & -2.089 & -2.488 \\
\hline VEN & -2.769 & -1.764 & -2.045 & PRY & -3.120 & -2.138 & -2.482 \\
\hline URY & -2.798 & -1.811 & -2.040 & UGA & -3.160 & -2.184 & -2.476 \\
\hline ZAF & -2.801 & -1.854 & -2.035 & LKA & -3.290 & -2.232 & -2.470 \\
\hline THA & -3.314 & -1.914 & -2.030 & VEN & -3.380 & -2.280 & -2.464 \\
\hline KEN & -3.335 & -1.971 & -2.025 & THA & -3.460 & -2.327 & -2.458 \\
\hline LKA & -3.335 & -2.024 & -2.020 & NGA & -3.610 & -2.377 & -2.452 \\
\hline GTM & -3.491 & -2.078 & -2.015 & MUS & -3.620 & -2.423 & -2.445 \\
\hline SLV & -3.519 & -2.130 & -2.010 & HND & -3.880 & -2.475 & -2.439 \\
\hline CHL & -3.602 & -2.180 & -2.005 & EGY & -3.890 & -2.524 & -2.433 \\
\hline PAN & -4.203 & -2.248 & -2.000 & KEN & -4.060 & -2.575 & -2.427 \\
\hline HND & -4.381 & -2.317 & -1.998 & NIC & -4.100 & -2.624 & -2.425 \\
\hline PAK & -4.448 & -2.383 & -1.996 & MAR & -4.290 & -2.676 & -2.422 \\
\hline MAR & -4.573 & -2.450 & -1.994 & PAN & -4.940 & -2.745 & -2.420 \\
\hline
\end{tabular}

See Table 6 and 8 notes. 